\title{
Investigation of Corrosion Resistance of poly(o- phenylenediamine)-ZnO Composites on Stainless Steel
}

\author{
Chaogang Zhou', Chaojin Zhou', Jiawei Zhang, ${ }^{3, *}$ \\ ${ }^{1}$ College of Metallurgy and Energy, Key Laboratory of the Ministry of Education for Modern \\ Metallurgy Technology, North China University of Science and Technology, Tangshan 063009, China \\ ${ }^{2}$ School of Materials Science and Engineering, Guangdong Provincial Key Laboratory of Advanced \\ Energy Storage Materials, South China University of Technology, Guangzhou 510641, China \\ ${ }^{3}$ School of Metallurgy, Northeastern University, Shenyang 110819, China \\ *E-mail: zhang416940558@163.com
}

doi: $10.20964 / 2019.08 .84$

Received: 31 March 2019 / Accepted: 20 May 2019 / Published: 30 June 2019

The poly(o-phenylenediamine)-ZnO (PoPD-ZnO) composite were synthesized by in-situ polymerization, and the waterborne polyurethane was used as the binder. The corrosion inhibition performance of the PoPD-ZnO composite coating on stainless steel was investigated. The structures of homopolymer PoPD and PoPD-ZnO composite were characterized by Fourier transform infrared spectroscopy (FTIR), X-ray diffraction (XRD) and scanning electron microscopy (SEM). Cyclic voltammetry demonstrates the redox properties and stability of the composite. After soaking in 3.5\% $\mathrm{NaCl}$ for a certain period of time, the corrosion resistance of the polymer coating was studied by potentiodynamic polarization and electrochemical impedance spectroscopy (EIS). The results show that the homopolymer PoPD coating and the PoPD-ZnO composite coating can protect the stainless steel. The corrosion rate of the PoPD-ZnO composite coating with good corrosion resistance is $1.9 \%$ of bare steel. In addition, the addition of nano- $\mathrm{ZnO}$ facilitates the formation of a compact and low-defect coating, thereby impeding the erosion of corrosive media and improving the corrosion resistance of PoPD coatings.

Keywords: poly(o-phenylenediamine) (PoPD); ZnO; Steel; polymer coating; anticorrosion

\section{FULL TEXT}

(C) 2019 The Authors. Published by ESG (www.electrochemsci.org). This article is an open access article distributed under the terms and conditions of the Creative Commons Attribution license (http://creativecommons.org/licenses/by/4.0/). 